\title{
Impact of Cultural Diversity on Overall Organizational Performance: A Moderating Role Education
}

\author{
Laar David Diam \\ Doctor of Philosophy in Management, Texila American University, Ghana
}

\begin{abstract}
This study focused on the impact of cultural diversity on organizational performance as moderated by employees' educational attainment. The study measured cultural diversity as language, religious and value system diversity. Organizational performance was measured as team building, communication, and employee productivity. The study collected primary data from 353 employees from ten different manufacturing companies in the Ashanti and Greater Accra Regions of Ghana. The study employed mean and standard deviation for descriptive analysis. The study employed a structural equation model for the estimation. Cultural diversity was found to be prevalence in the sampled companies. However, team building, and communication were effective, and employee productivity was high. The educational attainment of employees significantly reduced the negative impact of language, religious, and value system diversity on each organizational performance indicator. Stakeholders in Ghana's manufacturing industry should encourage continued human resource development through the pursuance of higher education, internal and external training, and seminars.
\end{abstract}

Keywords: Cultural Diversity, Educational attainment, Organizational Performance.

\section{Introduction}

Organizations and their workers operate in a distinct culture or socio-cultural context [1]. This is increasing in recent times because of globalization, where people from different socio-cultural backgrounds are hired by the organization [1], increasing cultural diversity in an organization. The term "diversity" refers to a group's variety and distinctions [2]. Individual distinctions such as ethnicity, age, religion, handicap status, geographic location, personality, sexual preferences, and a slew of other personal, demographic, and organizational traits can all be included in the definition of diversity. As a result, diversity may be a broad phrase that encompasses people from a variety of backgrounds [3].

Although mutual respect is the foundation of workplace diversity, accommodating each different worker's attitudes and opinions can be a huge task for companies, making diversity management challenging [4]. Employee work restrictions such as race, religion, and culture can be burdensome at times, especially if the organization's diversity is so great that the firm needs to hire a full-time staff to keep track of the employees' requirements [5]. Some Muslim employees, for example, may choose not to work on Fridays because it is a holy day for them. In such cases, employers must make arrangements for someone to fill in for them when the need arises.

Several organizations such as Canopy Health [6] have identified team building, employee productivity and communication as key indicators of organizational performance in a culturally diverse work environment. In a culturally diverse workplace, team building is a 
key tool employed by management to enhance productivity [7]. Effective team building can help achieve the vision and mission of an organization and help to foster a healthier workplace [8].

Employee productivity, on the other hand, as defined by Barcenas [89], is the amount of work (or output) produced by an employee in a specific period of time. Employees Productivity increases the overall efficiency of an organization $[9,10]$.

However, empirical studies on the impact of cultural diversity on organizational performance have produced mixed findings. For example, Mecheo [11] found that religion has a detrimental impact on employee productivity but has a positive impact on job dedication. Similarly, Oduro, Yalley, Sarpong, Kweitsu, and Danso [12] found that cultural diversity and its management has an impact on not just organizational competitiveness but also the organization's capacity to fulfill its objectives. Also, Qiaoxin and Liswandi [13] have shown that religion, language, and age all have a substantial impact on employee happiness, but gender has no impact on employee satisfaction in the firm.

Though the above studies and others have paid much attention to cultural diversity, less attention has been given to how the educational attainment of employees influences the relationship between cultural diversity and organizational performance indicators [14]. Though globalization is increasing, deeping the cultural diversity in organizations, literacy or educational attainment is increasing as well. Thus, the question is, does education effect the impact of cultural diversity on organizational performance indicators? This study sought to address this important vacuum in empirical studies.

This study would help to place cultural diversity in good perceptive in the phase of increasing the educational attainment of employees.

\section{Methods}

\section{Description of the Site}

This study was conducted in the Ashanti and Greater Accra Regions of Ghana. The Ashanti Region is located in south Ghana, and it is the third largest of 16 administrative regions, occupying a total land surface of $24,389 \mathrm{~km}^{2}$ $(9,417 \mathrm{sq} \mathrm{mi})$ or 10.2 percent of the total land area of Ghana. In terms of population, however, it is the most populated region with a population of 4,780,380 according to the 2010 census, accounting for $19.4 \%$ of Ghana's total population. Kumasi is the capital town of the Ashanti Region.

The Greater Accra Region is the smallest in terms of land area among the 16 administrative regions in Ghana. The region occupies a total land surface of 3,245 square kilometres. Greater Accra is the second populous region with a population of 4,010,054 in 2010, accounting for 16.3 percent of Ghana's total population [15]. The region is, however, the most urbanized where $87.4 \%$ of its population in lives in urban communities. Accra is the capital of the Greater Accra Region and the capital town of Ghana. These two regions host most of the Ghana's industries, manufacturing, services, construction, agro-processing, among others.

\section{Description of Experiment}

The study through Yamane [16] sample size determination formulae used 353 employees from ten manufacturing firms, as shown in Table 1. The employees were sampled from each firm using simple random sampling via the lottery method. The number of employees from each company is shown in Table 1 . 
Table 1. Population of Staff and Locations of the Accessible Companies

\begin{tabular}{|l|l|l|l|l|}
\hline No. & Companies & Staff population & Relative freq. (rf) & Sample size (rf*353) \\
\hline 1 & Guinness Ghana Breweries & 420 & 0.140 & 49 \\
\hline 2 & Dannex Ayrton Starwin Drugs & 713 & 0.237 & 84 \\
\hline 3 & Kasapreko & 437 & 0.145 & 51 \\
\hline 4 & Camelot Print Ghana & 66 & 0.022 & 8 \\
\hline 5 & Karma Pharmaceuticals & 235 & 0.078 & 28 \\
\hline 6 & Kinapharma Limited & 148 & 0.049 & 17 \\
\hline 7 & Latex foam & 66 & 0.022 & 8 \\
\hline 8 & Ashfoam & 83 & 0.028 & 10 \\
\hline 9 & Unilever: & 713 & 0.237 & 84 \\
\hline 10 & Tobinco Pharmaceuticals & 123 & 0.042 & 14 \\
\hline Total & 3,004 & 1.000 & 353 \\
\hline
\end{tabular}

Source: Administrations of the Selected Companies (July 2021)

The study used the questionnaire to collect the data from the staff of the selected companies. The questionnaire had four sections. Part I: Socio-demographic characteristics of respondents comprised of gender, age, educational level, religious affiliation, working experience, and tribe. Section II focused on culture diversity. The section had two subsections, including religion and the value system. Religion construct had nine (9) items, and whiles value system construct had nine (9) items. The items under of religious and value system diversities were adapted from Merk et al. (2017). Section III focused on communication, and the items under this were adapted from Mechheo (2014).

Communication competence had two main components, namely interpersonal skills (7 items) and cultural empathy (3 items). Section IV focused on team effectiveness, and it had 11 items. Section V focused on employee's Productivity and had 9 items. All the questions under each part (with the exception of Section I) were in the form of five-point Likert, ranging from strongly disagree to strongly agree.

The questionnaire was reliability with an overall Cronbach's Alpha of 0.887 (i.e., $\alpha=0.887$ ) and valid with Factor Loading Score for each item more than 0.4 and the KaiserMeyer-Olkin (KMO) for each construct was more than 0.8 .

\section{Statistical Method}

The data were analysed using Statistical Package for Social Sciences (SPSS), version 21.0, and STATA version 13.0. The study edited the data, coded the data, and entered them into the software for analysis. The study used SPSS for all the descriptive analysis, and whiles STATA was used to estimate of the model. The descriptive analysis was done using mean, standard deviations, skewness, and kurtosis. The mean score range of 1.00-3.49 is an indication that cultural diversity or organizational performance indicators are low. On the other hand, the mean score range of 3.50-5.00 suggests that cultural diversity and performance indicators are high.

To determine the effect of education on the impact of cultural diversity indicators (religion, language, and value system) on organization performance indicators (team building, communication, and employee productivity), this study used Structural Equation Model as suggested by Kline [17]. The models are specified below.

$$
\begin{aligned}
P R O D V=\propto_{0}+ & \propto_{1} \text { REL } * \text { EDUC }+\propto_{2} \text { LANG } \\
& * \text { EDUC }++\propto_{3} \text { VSYSTEM } \\
& * \text { EDUC }+\propto_{4} \text { GENDER } \\
& +\propto_{5} A G E \\
& +\varepsilon \ldots \ldots \ldots \ldots \ldots \text { Model } 1
\end{aligned}
$$




$$
\begin{array}{rl}
\text { TEAMB }=\propto_{0}+ & \propto_{1} \text { REL } * \text { EDUC }+\propto_{2} \text { LANG } \\
& * \text { EDUC }++\propto_{3} \text { VSYSTEM } \\
& * \text { EDUC }+\propto_{4} \text { GENDER } \\
& +\propto_{5} \text { AGE } \\
& +\varepsilon \ldots \ldots \ldots \ldots . . . . . \text { Model } 2 \\
\text { COM } \propto_{0}+\propto_{1} & R E L * E D U C+\propto_{2} \text { LANG } \\
& * E D U C++\propto_{3} \text { VSYSTEM } \\
& * \text { EDUC }+\propto_{4} \text { GENDER } \\
& +\propto_{5} \text { AGE } \\
& +\varepsilon \ldots \ldots \ldots \ldots \ldots \text { Model } 3
\end{array}
$$

Where PRODV is Productivity, TEAMB is team building, and COM is communication, REL*EDUC is the interaction of religious diversity and educational attainment, VSYSTEM*EDUC is the interaction of value system diversity and educational attainment, LANG*EDUC is the interaction of language diversity and educational attainment, GENDER is the gender of respondents and AGE is the age of respondents. Team building, communication, and employee productivity were measured qualitatively based on a scale by Mechheo [18]. The cultural diversity (language, religious and value system diversity) were measured based on a scale by Merk [19]. Age was a continuous variables, while gender was a nominal variable with a female as the reference category.

\section{Results}

\section{Socio-demographic Characteristics of the Respondents}

\begin{tabular}{|c|c|c|c|}
\hline Characteristics & Variable & Frequency (N) & Percentage (\%) \\
\hline \multirow[t]{2}{*}{ Sex } & Male & 195 & 55.2 \\
\hline & Female & 158 & 44.8 \\
\hline \multirow[t]{7}{*}{ Educational Attainment } & None & 16 & 4.5 \\
\hline & Basic School & 35 & 9.9 \\
\hline & Senior High & 85 & 24.1 \\
\hline & Diploma/HND & 68 & 19.3 \\
\hline & First Degree & 92 & 261 \\
\hline & Masters' Degree & 43 & 12.2 \\
\hline & $\mathrm{PhD}$ & 14 & 4.0 \\
\hline \multirow[t]{4}{*}{ Level of Experience } & Less than 5 years & 62 & 17.6 \\
\hline & $5-9$ years & 127 & 36.0 \\
\hline & $10-14$ years & 126 & 35. \\
\hline & At least 15 years & 38 & 10.8 \\
\hline \multirow[t]{5}{*}{ Religious Affiliation } & Atheist & 5 & 1.4 \\
\hline & Christian & 167 & 47.3 \\
\hline & Muslim & 125 & 35.4 \\
\hline & Traditionalist & 43 & 12.2 \\
\hline & Buddhist & 13 & 3.7 \\
\hline \multirow[t]{4}{*}{ Tribe } & Akan & 122 & 34.6 \\
\hline & Hausa & 67 & 19.0 \\
\hline & Mole-Dagbani & 22 & 6.2 \\
\hline & Ewe & 43 & 12.2 \\
\hline
\end{tabular}

As part of the survey, data were gathered on the demographic characteristics of the various respondents considered in this study. The main aspects of the socio-demographic characteristics of the respondents included sex, educational attainment, level of experience of working in the organization, religious affiliation, and the tribe of these respondents. A summary of the results is displayed in Table 2 .

Table 2. Socio-Demographic Characteristics of Respondents 


\begin{tabular}{|l|l|l|l|}
\hline & Nzema & 32 & 9.1 \\
\cline { 2 - 4 } & Krobo/Ga/Adangbe & 49 & 13.9 \\
\cline { 2 - 4 } & Others & 18 & 5.1 \\
\hline
\end{tabular}

Source: Field Data (2021)

From the results, though males dominated over females, the gap is very close. The higher number of employees had at least second cycle education, a cumulative of which is $85.7 \%$ of the entire population. Table 2 reports that the majority of the respondents had at most 5 years of working experience. Table 2 reports that 5 (1.4\%), 167 (47.3\%), 125 (35.4\%), 43 (12.2\%), and $13(3.7 \%)$ of the employees considered in this study were Atheists, Christians, Muslims, Traditionalists, and Buddhists respectively.

\section{Descriptions of Study Variables}

The key variables used in this study are described in Table 3.

Table 3. Descriptions of Study Variables

\begin{tabular}{|l|l|l|l|l|l|l|l|}
\hline $\begin{array}{l}\text { Main } \\
\text { Variables }\end{array}$ & Specific variables & Min. & Max. & Mean & Std. & Skewness & Kurtosis \\
\hline $\begin{array}{l}\text { Cultural } \\
\text { diversity }\end{array}$ & Religion & 1 & 5 & 3.8677 & 0.1181 & -0.003 & -0.824 \\
\cline { 2 - 8 } & Value system & 1 & 5 & 3.6956 & 1.0061 & -0.617 & 0.330 \\
\hline $\begin{array}{l}\text { Performance } \\
\text { indicators }\end{array}$ & Team building & 1 & 5 & 3.3732 & 0.9345 & 0.325 & 0.276 \\
\cline { 2 - 8 } & Communication & 1 & 5 & 3.7377 & 1.0113 & -0.216 & -0.583 \\
\cline { 2 - 8 } & $\begin{array}{l}\text { Employee } \\
\text { productivity }\end{array}$ & 1 & 5 & 4.0019 & 0.1817 & 0.316 & 0.438 \\
\hline
\end{tabular}

Source: Filed Data (2021)

The results in Table 3 show that cultural diversity in the areas of religion and value system were eminent in the sampled organization. The sampled companies had high team building, organizational communication, and employee productivity.

\section{Estimation of the Models}

The study first estimated the impact of cultural diversity on performance indicators without the moderating role of education, as shown in Table 4.

Table 4. Impact of Cultural Diversity on Organizational Performance

\begin{tabular}{|l|l|l|l|}
\hline \multirow{2}{*}{ Variables } & Model 1 & Model 2 & Model 3 \\
\cline { 2 - 4 } & (Team Building) & (Communication) & (Employee Productivity) \\
\hline \multirow{3}{*}{ Language diversity } & -0.0047 & -.0260 & -0.4316 \\
\cline { 2 - 4 } & $(0.0269)$ & $(0.0516)$ & $(0.0519)^{* *}$ \\
\hline Religious diversity & -0.0314 & -.0726 & -0.0289 \\
\cline { 2 - 4 } & $(0.0203)$ & $(0.0389)$ & $(0.0392)$ \\
\hline Value system diversity & -0.1853 & .2069 & -0.5416 \\
\cline { 2 - 4 } & $(0.0649)^{*}$ & $(0.1244)$ & $(0.1253)^{* *}$ \\
\hline \multirow{3}{*}{ Gender } & -0.0498 & -.0311 & -.0690 \\
\cline { 2 - 4 } & $(0.0377)$ & $(0.0723)$ & $(0.0729)$ \\
\hline \multirow{2}{*}{ Educational attainment } & 0.0844 & .0577 & .1521 \\
\cline { 2 - 4 } & $(0.0138)^{* *}$ & $(0.0265)^{*}$ & $(0.0268)^{* *}$ \\
\hline \multirow{2}{*}{$\begin{array}{l}\text { Years of working } \\
\text { experience }\end{array}$} & -0.0926 & 0.0146 & -.0205 \\
\cline { 2 - 4 } & $(0.0228)^{* *}$ & $(0.0438)$ & $(.0441)$ \\
\hline
\end{tabular}




\begin{tabular}{|l|l|l|l|}
\hline \multirow{2}{*}{ Constant } & 4.3798 & 2.6678 & 4.4913 \\
\cline { 2 - 4 } & $\left(0.2773^{* *}\right)$ & $(0.5319)^{* *}$ & $(0.5357)$ \\
\hline Chi-sq. & 74.912 & 13.270 & 123.807 \\
\hline p-value & 0.000 & 0.039 & 0.000 \\
\hline
\end{tabular}

Source: Field Data (2021)

From Table 4, language diversity significantly reduces employee productivity $(\beta=$ -0.4316) but had no significant impact on team building and communication. Religious diversity had no significant impact on team building, communication, and employee productivity. Value system diversity had a significant negative impact on team building ( $\beta$

$=-0.1853)$ and employee productivity $(\beta=-$ $0.5416)$.

The study further estimates the moderation role of education in the impact of cultural diversity indicators on organizational performance indicators to determine the impact would be in the presence of education, and the results are summarized in Table 5.

Table 5. Role of Education on the Impact of Cultural Diversity on Organizational Performance Indicators

\begin{tabular}{|c|c|c|c|c|c|c|c|c|c|}
\hline \multicolumn{10}{|l|}{ Model } \\
\hline \multirow[t]{2}{*}{ Variables } & \multicolumn{3}{|c|}{ Communication Effectiveness } & \multicolumn{3}{|c|}{ Team Effectiveness } & \multicolumn{3}{|c|}{ Productivity } \\
\hline & Coef. & Std. Err & $\mathbf{p}>|\mathbf{z}|$ & Coef. & Std. Err & $\mathbf{p}>|\mathbf{z}|$ & Coef. & Std. Err & $\mathbf{p}>|\mathbf{z}|$ \\
\hline Lang*Edu & .0001823 & .0124737 & 0.988 & $-.009374)$ & .0066587 & 0.159 & .0881448 & .0131782 & 0.000 \\
\hline Relig*Edu & -.0268523 & .0091781 & 0.003 & .0142465 & .0048994 & 0.004 & .0035617 & .0096964 & 0.713 \\
\hline Value*Edu & .0324529 & .0117846 & 0.006 & $.0135124)$ & .0375523 & 0.032 & -.0139407 & .0124502 & 0.263 \\
\hline Gender & -.0411628 & .070347 & 0.558 & -.0203443 & .035523 & 0.588 & -.004836 & .0743198 & 0.948 \\
\hline YExp & .0178142 & .0421847 & 0.673 & -.0914127 & .0225189 & 0.000 & -.0431194 & .0445671 & 0.333 \\
\hline _cons & 3.225698 & .1950056 & 0.000 & 3.77766 & .104097 & 0.000 & 3.252543 & .2060185 & 0.000 \\
\hline Chi2_bs (6) & 17.306 & & & 62.247 & & & 94.097 & $\begin{array}{l}\text { Baseline vs } \\
\text { saturated }\end{array}$ & \\
\hline p>chi2 & 0.004 & & & 0.000 & & & 0.000 & & \\
\hline
\end{tabular}

Source: Field Data (2021); Lang*Edu=Language Diversity moderated by educational attainment; Reli*Edu=Religious diversity moderated by educational attainment; Value*Edu= Value Diversity moderated by educational attainment; YExp=Years of working in the Organization

Table 5 reports that, amongst highly educated employees, language diversity does not have significant influence on communication effectiveness $(\beta=.0001823 ; p$-value $=0.988)$ and team effectiveness $(\beta=-.009374 ; \mathrm{p}$-value $=$ 0.159). These statistics, however, suggests that, among the educated workforce, language diversity significantly improves Productivity $(\beta=0.881448$; $p$-value $=0.000)$ in the workplace. Table 5 reports that education moderates the influence of religious beliefs in the workplace. These statistics indicates that, interaction of education and religious diversity significantly reduces communication effectiveness $(\beta=$ $.0268523 ; \mathrm{p}$-value $=0.003$ ) but significantly improves team effectiveness $(\beta=.0142465$; $\mathrm{p}$ value $=0.004)$.

However, interaction of education and religious diversity did not significantly influence productivity $(\beta=.0035617$; $\mathrm{p}$-value $=0.713)$ in the workplace. Table 5 reports that, amongst educated employee's employee value system significantly improves communication effectiveness $(\beta=.0324529 ; \mathrm{p}$-value $=0.006)$ and team effectives $(\beta=.0135124 ; \mathrm{p}=$ value $=0.032)$. However, the interaction of education and value system did not significantly influence employee productivity $(\beta=-.0139407$; $p$-value $=0.263)$ in the workplace. 


\section{Discussions}

Thus, inferring from the results, as the level of education of employees increases, the detrimental effects of language diversity on communication and team building is minimized, which leads to improving Productivity. Comparing the effects of employee language diversity on Productivity prior to the inclusion of the moderator variable in the model and after estimating the model, it can be seen that there is a higher change in productivity coefficient. Hence, education influences the role of language diversity on Productivity through enhanced skills set and communication competence of employees [14]. Chenov and Chernova [19] are also of the view that educational competence is unquestionably a competitive advantage for individuals working in culturally diverse business settings as it enhances employee productivity. Neo [20] posits that it is critical for employees to understand how people from various cross-cultural backgrounds interpret, communicate, and make decisions. Education now becomes a key variable in this endeavour which may have impacts on the degree of communication and enhance the Productivity in the workplace. Although it may be difficult to comprehend some comments and behaviours, education leads to a shared notion of acceptance and open-mindedness. These may have significant impacts on Productivity in the workplace.

Also, education leads to a sense of tolerance which makes the effects of employee religion on team building seemingly negligent. Peltonen's [21] indicated that religion, like ethnocentrism and stereotyping, hinders communication by creating a distinct picture of individuals who follow various religions irrespective of the level of education of these individual. Persons find it challenging to communicate with people of various religious beliefs. People's attitudes toward others are influenced by their religious beliefs. As a result, even very education which has been tried and proved may not be sufficient to completely eliminate the impact of religion in the workplace, which may have negative consequences for overall company efficiency. Piga [22] provides contradiction to these findings when he found that good education may remedy the negative impacts of religiosity in the workplace. Hence, when employees are highly educated, the negative impact of cultural diversity is minimized.

Similarly, education reduces the negative impact of value system diversity on communication, team building, and Productivity. The results in this study are in line with Mecheo's [11] results, which indicated that cultural values had a favorable impact on organizational performance. According to Barret [23], an employee can react with every circumstance in one of three ways. They can respond using their beliefs, ideals, or intuition. Barrett goes on to say that if workers make judgments based on their views, such conclusions would reflect their previous experience dealing with comparable situations, making the decision a gamble. Past history is constantly lived and contextualized, and beliefs are unprepared to deal with complicated new situations that have never been encountered before. As a result, in the absence of education and training programmes, in the workplace, workers may make judgments based on their own values and beliefs, which may not be the best option for the company and may have an influence on how they operate and their overall performance.

The result in this study further provides support for Ringov [24] in their work which indicated that education and training enable employees to discover genuine and meaningful alignment between their personal values and that of the organization, a strong relationship is formed in such instances. This link opens up a slew of opportunities for personal development and business productivity, manifesting itself in a variety of ways, including reducing the impacts of employee value diversity in favour of a single common company value system. As a result, when a company and its employees join together 
around a same set of values, they become more flexible, less hierarchical, and less bureaucratic, and they build a stronger capacity for collective action. When employees share not only identical values, but also a same vision, a company's performance improves.

\section{Conclusion}

The study aimed at assessing the effects education in the impact of cultural diversity on organizational performance, using various manufacturing companies in Ghana. It was observed that cultural diversity is high as well as team building, communication, and Productivity. The study concludes that education plays a crucial moderating role by minimizing the negative impact of cultural diversity on team building, communication, and employee productivity.

Based on these findings, employees should be encouraged to undergoing constant training in cultural diversity and further their education to enhance their knowledge, skills, and exposure. This will help the employees to relate well with each other, despite their cultural differences, to help improve organizational performance.

Despite interesting findings in this paper, the researcher believes that the implications of

\section{References}

[1] Hofstede, G. (2001). Cultural Consequences: Comparing values, behaviors, institutions, and Organizations across nations. (2nd ed) Thousand oaks, ca: sage publication inc.

[2] Nile, M. \& Dyer, G. (2004). Human capital and learning as a source of sustainable competitive advantage Strategic Management Journal Volume 25, Issue 12, pages 1155-1178.

[3] Herring, C. (2009). Does diversity pay? Race, gender, and the business case for diversity. American sociological review, 74(2), 208-224.

[4] Ashton, V. (2010). Does ethnicity matter? Social workers' personal attitudes and professional behaviors in reporting child maltreatment. Advances in Social Work, 11(2), 129-143. cultural diversity can be far stretched than just three variables that were studied. Therefore, further research may focus on exploring the implications of cultural diversity on other variables like employee retention/commitment, employee job satisfaction, global competitiveness of organizations, among others.

\section{Acknowledgement}

My sincerest gratitude to Dr. Freda Ocansey, Mr. Prince Amoako who offered very valuable contributions and were very supportive in the compilation of this article. I take this opportunity to thank Anitha, my research mentor, my office secretary, who did the typesetting of this manuscript. Ms. Mary Yigal, how can I forget you? Your kindness and love were just indescribable.

I will remain grateful. Mrs. Diam Lilian Laar, my wife, you were, and you remain my solid aids and support. I could not have made it without you.

\section{Conflict of Interest}

The author declares that there is no conflict of interest with regards to this paper.

[5] Dike, P. (2013). The impact of workplace diversity on organisations.

[6] Canopy Health. (2018). Productive TeamBuilding Exercises at the Workplace. Canopy Health. [7] Bright HR. (2020). The Importance of Teamwork in the Workplace Bright HR undefined. Brighthr.com. [8] Brady, D. (2016). The Positive Impact of Team Building - TTB. Total Team Building.

[9] Barcenas, M. (2020). Employee Productivity: The Ultimate Guide for Managers. Fellow.app.

[10] Yoshifumi, H., Sammogram, S., \& ManzumaNdaaba, N. M. (2018). Effect of Productivity and Perceived Quality on Organizational Performance from Lean Management Practice Perspective. Science Alert.

[11] Mecheo, K. N. (2016). The Effect of Employee Cultural Diversity on Organizational Performance: 
A Case Study of Oilybia-Kenya (Doctoral dissertation, United States International UniversityAfrica).

[12]Danso, L., Oduro, F., Yalley, F., Sarpong, A., \& Tetteh Kweitsu, M. A. R. T. I. N. (2019). Management of Cultural Diversity: Implication for Organizational Competitiveness. A Case Study of Asokore Rural Bank Limited, of orikrom and Kwadaso Branches, Kumasi (Doctoral dissertation). [13] Qiaoxin, M., \& Liswandi, L. (2018). Analysis of Cultural Diversity Factors Influencing Employees Satisfaction. International Journal of Management, Accounting and Economics, 5(12), 955-965.

[14] Abugre, J. B., \& Debrah, Y. A. (2019). Assessing the impact of cross-cultural communication competence on expatriate business operations in multinational corporations of a Sub-Saharan African context. International Journal of Cross-Cultural Management, 19(1), 85-104.

[15] Ghana Statistical Service, 2010 Population and Housing Census.

[16] Yamane, T., (1967). Elementary Sampling Theory, New Jersey: Prentice-Hall, here is a list of some books, articles, and websites that either used Slovin's formula inappropriately or presented the formula without mentioning its assumptions.

[17] Kline, R. B. (2011). Principles and practice of structural equation modeling (3rd ed.). Guilford Press.
[18]Mechheo, C.W. (2014), Effects of Communication strategies on organizational performance: A case study of Kenya ports authority. European Journal of Business and Management 6(11) 6- 10. Retrieved from www.iiste.org.

[19] Chernov, S. \& Chernova, L. (2018). Algorithm for the simplification of solution to discrete optimization problems. Eastern European Journal of Advanced Technologies, (3 (4)), 34-43.

[20]Neo, H. (2015). Modelling green urbanism in China. Area, 47(2), 132-140.

[21]Peltonen, K. (2019). From Cultural Differences to Identity Politics: A Critical Discursive Approach to National Identity in Professor.

[22]Piga, D. (2020). Computation of Parameter Dependent Robust Invariant Sets for LPV Models with Guaranteed Performance. arXiv preprint arXiv:2009.09778.

[23] Barret, O., (2005). Monte Carlo simulation and scatter correction of the GE advance PET scanner with SimSET and Geant4. Physics in Medicine \& Biology, 50(20), 4823.

[24]Ringov, D., \& Zollo, M. (2017). The impact of national culture on corporate social performance. Corporate Governance: The international Journal of business in society, 7(4), 476-485. 